\title{
Dietary Indicators of Oral and Pharyngeal Cancer
}

\author{
CARLO LA VECCHIA***, EVA NEGRI*, BARBARA D'AVANZO*, PETER BOYLE† AND \\ SILVIA FRANCESCHIF
}

\begin{abstract}
Le Vecchia C (Istituto di Ricerche Farmacologiche 'Mario Negri' Via Eritrea 62, 20157 Milen, Italy). Negri E, D'Avanzo B, Boyle $P$ and Franceschi S. Dietary indicators of oral and pharyngeal cancer. International Journa/ of Epidemiology 1991, 20: $39-44$.

The relationship between frequency of consumption of a selected number of indicator foods and oral and oropharyngeal cancer risk was analysed in a case-control study conducted in Northern Italy on 105 cases of oral and pharyngeal cancer and 1169 controls in hospital for acute, non-neoplastic or digestive diseases. Besides significant and strong direct associations with tobacco (relative risk, RR = 11.0 for current versus never smokers) and alcohol (RR = 5.8 for upper versus lower consumption tertile), consumption of six food items (milk, meat, cheese, carrots, green vegetables and fruit) were inversely and significantly related to oral and pharyngeal cancer risk. The strongest protection was apparently related to frequent fruit consumption, with RRs of 0.8 and 0.2 in the two highest tertiles. Allowance for major potential confounding factors, including tobacco, alcohol and social class indicators explained only part of the dietary correlates observed. The two items remaining significant after multivariate analysis were fruit (RR $=0.3$ for the upper tertile) and alcohol (RR $=3.8$ for the upper tertile). The associations observed may simply reflect a generally poorer nutritional status in the cases, although the observation that fruit consumption appears to be a particularly important protective factor against oropharyngeal cancer is of potential interest, in terms of aetiological clues and preventive implications.
\end{abstract}

There are several suggestions that nutritional factors, and specifically dietary deficiencies, are associated with the risk of oral and pharyngeal cancer.

Iron deficiency and primary sideropenic anaemia, since their first description early in this century, have been associated with malignancies of the upper digestive tract. ${ }^{1.2}$ This syndrome (Plummer Vinson or Paterson-Brown-Kelly) was particularly common in Northern European countries, but the risk of these cancers was not associated with iron deficiency in tropical countries, and similar lesions were not produced by an iron-deficient diet in animals. ${ }^{3}$ Thus, other nutritional deficiencies are likely to be implicated, including those of niacin, riboflavin, thiamine and pyridoxine..$^{2,46}$ Diffuse lesions of the upper alimentary tract were also observed in pellagra, a disease endemic in the Midwestern and Southern United States as well as in Central Europe and Northern Italy up to the beginning of this century, which was due to niacin deficiency

'Istituto di Ricerche Farmacologiche 'Mario Negri', Via Eritrea 62, 20157 Milano, Italy.

*Institute of Sacial and Preventive Medicine, University of Lausanne, 1005 Lausanne, Switzerland.

tThe International Agency for Research on Cancer, 69372 Lyon, France.

†Aviano Cancer Centre, 33081 Aviano, Pordenone, Italy. and entails widespread inflammation of the mucous surfaces of the oral cavity, pharynx and oesophagus with consequent dysphagia. ${ }^{\text {? }}$

Over the last decades, formal epidemiological studies have been published on dietary correlates of oral cancer. Although earlier work found little association with any specific dietary item or method of preparation, ${ }^{8}$ subsequent studies showed decreased risks with increasing consumption of Vitamin $\mathrm{A}$ and $\mathrm{C}$, fresh fruit, green leaf vegetables and other vegetables. ${ }^{10}$ More recent work from Brazil, ${ }^{11}$ as well as a large, population-based study conducted in four areas of the US ${ }^{12}$ seemed to point to specific protection by fruit or citrus fruit intake, which was not accounted for by the Vitamin $\mathrm{C}$, carotene or fibre content in fruit or vegetables.

To provide further information on the issue, the relationship between a few selected indicators foods and cancer of the mouth and pharynx was investigated using data from a case-control study conducted in northern Italy. This is a relatively high incidence and mortality area, both on a national and European scale. $^{13,14}$

\section{SUBJECTS AND METHODS}

The general design of this ongoing study of upper 
digestive and respiratory tract neoplasms, based on a network including teaching and general hospitals in the Greater Milan area, northern Italy, has already been described. ${ }^{15}$ Within this study scheme, trained interviewers identified and questioned patients admitted to university and general hospitals in the area under surveillance for the cancer sites of interest and a wide spectrum of other conditions. All the interviews were conducted in hospitals, and based on information provided by the patients (no proxy was identified for deceased or ill subjects). Telephone replication of selected sections of the interview (including the dietary one), performed a few weeks later on a subsample of approximately $10 \%$ of cases and controls, provided information on questionnaire validity and reproducibility, and interview reliability.

Recruitment of cases of oral and pharyngeal cancer started in January 1987, and the present analysis is based on data collected before December 1989.

The cases studied were patients under the age of 75 years who had been admitted for histologically confirmed oral $(n=35)$ or oro-pharyngeal $(n=70)$ cancer to the National Cancer Institute and the Ospedale Maggiore, which includes the four largest teaching and general hospitals in Milan. Cancers of the nasopharynx and salivary gland were excluded. Only incident cases (i.e. whose diagnosis was made within the year before interview) were considered. Among 105 cases interviewed, 89 were males and 16 females. The age range was 37 to 74 , and median age 56 years.

The comparison group comprised 1169 subjects ( 875 males, 294 females), admitted to the same network of hospitals for acute, non-neoplastic or digestive diseases, unrelated to alcohol or tobacco consumption. The age range was 21 to 74 , and the median age 55 years. Thirty-two per cent were admitted for trauma, $15 \%$ for non-traumatic orthopaedic conditions, $39 \%$ had acute surgical diseases, and $14 \%$ other miscellaneous disorders, including acute infections, skin, eye diseases, etc.

The catchment area of cases and controls was comparable: $83 \%$ of the cases and controls resided in the same region-Lombardy- $91 \%$ of the cases and $94 \%$ of the controls came from northern Italy. On average, less than $3 \%$ of eligible subjects (cases and controls) refused to be interviewed.

Information was collected using a structured questionnaire on socio-demographic factors, personal characteristics and habits; use of tobacco and alcohol in various forms, coffee and other methylxanthinecontaining beverages; related personal and family medical history; and specific use of drugs. Questions on alcohol included the number of days per week each type of alcoholic beverage (wine, beer and spirits) was consumed, the average number of drinks per day, and the duration of the habit in years. Data were also collected on the usual frequency of consumption per week of ten indicator foods before the onset of symptoms of the disease which led to hospital admission, and simple subjective scores (low, intermediate, high) were used as measures of use of wholemeal bread or pasta and of various fats in condiment (butter, margarine, oil). Thus, a total of 17 food items were considered in this report. All information referred to the patients' behaviour before the onset of the symptoms which led to hospital admission.

\section{Data Analysis}

Measures of indicator food consumption were subdivided into three levels including, as far as possible, comparable proportions of cases and controls combined (approximate tertiles, although based on discrete frequencies and consequently unevenly distributed for several food items). Total alcohol consumption was computed as the sum of wine, beer and other types of alcoholic beverages, assuming a comparable content of ethanol in each type of drink (i.e. $150 \mathrm{ml}$ of wine $=330 \mathrm{ml}$ of beer $=30 \mathrm{ml}$ of spirits = approximately $12 \mathrm{ml}$ of ethanol).

Relative risks (RRs) of oropharyngeal cancer, together with their $95 \%$ approximate confidence intervals $(\mathrm{Cls}),{ }^{16}$ were first computed from data stratified for sex and decade of age by means of the usual Mantel-Haenszel procedure. ${ }^{17}$ Significance was assessed by the linear trend test described by Mantel. ${ }^{18}$

To account simultaneously for the potential confounding effect of major identified covariates, multiple logistic regression was used, ${ }^{19}$ including terms for age, area of residence (Lombardy versus other), education, social class, and smoking. Finally, since various food items may act to confound each other, models were produced including various dietary factors simultaneously.

\section{RESULTS}

Table 1 gives the distribution of cases and controls according to sex, age, education and smoking habits. The median ages of cases and controls were comparable, but oropharyngeal cancer cases were substantially less educated than controls: the age- and sex-adjusted RR for the lowest versus highest level of education was $6.2(95 \% \mathrm{CI}=3.2-12.5)$. A similarly strong inverse association emerged when head of the household's occupation was used as an indicator of social class. Smoking was the strongest determinant of oropharyngeal cancer risk in this study: compared to 
TABLE 1 Distribution of 105 cases of oral and pharyngeal cancer and 1169 controls according to sex, age, educarion and smoking habits. Milan, Jtaly $1987-89$

\begin{tabular}{|c|c|c|c|c|}
\hline & \multicolumn{2}{|c|}{ Oral and pharyngeal cancer } & \multicolumn{2}{|c|}{ Controls } \\
\hline & Number & $x_{0}$ & Number & $\%$ \\
\hline \multicolumn{5}{|l|}{$\operatorname{sex}$} \\
\hline Males & 89 & 84.8 & 875 & 74.9 \\
\hline Females & 16 & 15.2 & 294 & 25.1 \\
\hline \multicolumn{5}{|l|}{ Age } \\
\hline$<45$ & 7 & 6.7 & 235 & 20.1 \\
\hline $45-54$ & 39 & 37.1 & 330 & 28.2 \\
\hline $55-64$ & 41 & 39.0 & 353 & 30.2 \\
\hline $65-74$ & 18 & 17.1 & 251 & 21.5 \\
\hline \multicolumn{5}{|l|}{ Education (years)* } \\
\hline$<7$ & 80 & 76.2 & 552 & 47.2 \\
\hline $7-11$ & 18 & 17.1 & 349 & 29.9 \\
\hline$\geq 12$ & 7 & 6.7 & 260 & 22.2 \\
\hline \multicolumn{5}{|l|}{ Smoking habits } \\
\hline Never smokers & 8 & 7.6 & 423 & 36.2 \\
\hline Ex-smokers & 11 & 10.5 & 244 & 20.9 \\
\hline Pipe/cigar smokers & 2 & 1.9 & 7 & 0.6 \\
\hline \multicolumn{5}{|l|}{ Cigarette smokers } \\
\hline$<15 /$ day & 10 & 9.5 & 167 & 14.3 \\
\hline 15-24/day & 51 & 48.6 & 205 & 17.5 \\
\hline$\geq 25 /$ day & 23 & 21.9 & 123 & 10.5 \\
\hline
\end{tabular}

*The sum of strata does not add up to the total because of missing values.

never smokers, the RR was 4.3 for ex-smokers, 11.0 for current smokers, and rose to $\mathbf{1 7 . 9}$ for heavy smokers.

Available indicator foods are presented in Table 2 in terms of distribution into approximate frequency tertiles and corresponding age- and sex-adjusted relative risks. Among 17 items considered, six (milk, meat, cheese, carrots, green vegetables and fruit) were inversely and significantly related to oral and pharyngeal cancer risk. The strongest protection was apparently associated with more frequent fruit consumption, with RRs of 0.6 and 0.1 in the intermediate and highest tertiles. No relation emerged with wholemeal bread or pasta, various types of fats, or coffee, while alcohol consumption was directly related to oral and pharyngeal cancer: compared with subjects drinking less than four drinks per day, the RR was 1.7 for four to six and 5.8 for over six drinks per day.

The items showing significant associations were further analysed in two series of multiple logistic regression equations, including (i) the major non-dietary covariates, and (ii) both non-dietary variables and food items (Table 3). Allowance for a number of identified potential distorting factors explained only part of the associations observed, but a significant relationship was still evident after multivariate analysis for alcohol ( $R R=3.8$ for the upper consumption tertile), and a significant protection remained for fresh fruit
( $R R=0.3$ for the upper tertile). Thus, although interpretation of the models simultaneously including various food items is hampered by problems of collinearity between various terms, these results may be taken as suggestive evidence that alcohol and fruit are the most relevant (respectively risk and protective) factors in oropharyngeal carcinogenesis.

Table 4 presents the relationship with fruit consumption in separate strata of tobacco and alcohol consumption. No appreciable interaction emerged with these two major identified risk factors for oral and pharyngeal cancer, and the pattern of risk was consistent across various strata examined.

\section{DISCUSSION}

The results of this study are in broad agreement with previous work, and in particular confirm that tobacco and alcohol are the strongest determinants of oral and pharyogeal cancer risk in developed countries. ${ }^{3,4,20-22}$ Further, they indicate that the disease has consistently negative socioeconomic correlates, and suggest that a poor diet is probably an independent factor influencing carcinogenesis for the oral cavity and pharynx. The relative risk was decreased by 40 to $70 \%$ in the upper tertile of consumption of milk, meat, fruit and vegetables, which represent indicators of a more affluent diet in this population. The strongest protective effect was apparently given by fruit, and the protection was consistent across strata of tobacco and alcohol and persisted after allowance for other food items was made using multivariate analysis.

This is consistent with the results of a large, population based case-control study conducted in several areas of the US, ${ }^{12}$ which found a significant protection by fruit and several nutrients with fruit as a major source (Vitamin C, carotene, fibre), but no association with vegetables or with the same nutrients in vegetables. Similar strong protective effects of fruit intake have been observed in studies on oesophageal ${ }^{23.24}$ and laryngeal ${ }^{25.26}$ cancers.

It is difficult, nonetheless, to formulate hypotheses on which component of fruit may be specifically protective, or whether a diet rich in fruit simply represents a non-specific favourable indicator of risk. The questionnaire sought consumption information on a number of important sources of Vitamin $A$ in the Italian diet and, although based on a restricted selection of indicator foods, may be sufficient to study this micro-nutrient. ${ }^{27}$ As in a previous American study ${ }^{28}$ carotenoids, but not retinoids, were inversely related with risk of cancer of the oral cavity and pharynx, but the association was weaker than that with measures of fruit consumption (RR for the upper tertile $=0.3$, 


\begin{tabular}{|c|c|c|c|c|c|c|c|c|}
\hline \multirow[b]{2}{*}{ Food or beverage } & \multirow[b]{2}{*}{$\begin{array}{l}\text { Frequency of } \\
\text { consumption }\end{array}$} & \multicolumn{3}{|c|}{$\begin{array}{l}\text { Frequency of consumption } \\
\text { No. of cases: No. of controlst }\end{array}$} & \multicolumn{3}{|c|}{ Relative risk estimatesł } & \multirow[b]{2}{*}{$p$ value } \\
\hline & & $\begin{array}{c}1 \\
\text { (Low) }\end{array}$ & $\begin{array}{c}2 \\
\text { (Intermediate) }\end{array}$ & $\begin{array}{c}3 \\
\text { (High) }\end{array}$ & $\begin{array}{c}1 \\
(\text { Low })\end{array}$ & $\begin{array}{c}2 \\
\text { (Intermediate) }\end{array}$ & $\begin{array}{c}3 \\
(\text { High })\end{array}$ & \\
\hline Milk & $<1 ; 1-7 ;>7$ & $49: 439$ & $48: 511$ & $8: 218$ & $1 S$ & $\begin{array}{c}0.8 \\
(0.5-1.2)\end{array}$ & $\begin{array}{c}0.3 \\
(0.2-0.7)\end{array}$ & $<0.01$ \\
\hline Meat & $<4 ; 4-6 ;>6$ & $43: 365$ & $42: 363$ & $20: 441$ & is & $\begin{array}{c}1.0 \\
(0.6-1.5)\end{array}$ & $\begin{array}{c}0.4 \\
(0.2-0.7)\end{array}$ & $<0.001$ \\
\hline Liver & $<1 ; 1 ;>1$ & $80: 917$ & $20: 210$ & $5: 42$ & 1S & $\begin{array}{c}1.1 \\
(0.7-1.9)\end{array}$ & $\begin{array}{c}1.4 \\
(0.5-3.7)\end{array}$ & n.s \\
\hline Eggs & $<1 ; 1 ;>1$ & $25: 339$ & $19: 256$ & $61: 573$ & is & $\begin{array}{c}1.0 \\
(0.5-1.9)\end{array}$ & $\begin{array}{c}1.5 \\
(0.9-2.4)\end{array}$ & $\mathrm{n} . \mathrm{s}$ \\
\hline Ham \& salami & $<2 ; 2 ;>2$ & $36: 423$ & $28: 344$ & $41: 402$ & 15 & $\begin{array}{c}0.9 \\
(0.6-1.6)\end{array}$ & $\begin{array}{c}1.2 \\
(0.7-1.9)\end{array}$ & n.s \\
\hline Fish & $<1 ; 1 ;>1$ & $46: 457$ & $41: 465$ & $18: 246$ & 1S & $\begin{array}{c}0.9 \\
(0.5-1.3)\end{array}$ & $\begin{array}{c}0.7 \\
(0.4-1.3)\end{array}$ & n.s. \\
\hline Cheese & $<4 ; 4-6 ; \geq 6$ & $41: 382$ & $44: 313$ & $30: 474$ & $1 \mathrm{~S}$ & $\begin{array}{c}1.0 \\
(0.6-1.6)\end{array}$ & $\begin{array}{c}0.6 \\
(0.4-0.9)\end{array}$ & $<0.05$ \\
\hline Carrots & $<1 ; 1 ;>1$ & $68: 550$ & $22: 291$ & $15: 326$ & $1 S$ & $\begin{array}{c}0.6 \\
(0.4-1.0)\end{array}$ & $\begin{array}{c}0.4 \\
(0.2-0.7)\end{array}$ & $<0.001$ \\
\hline $\begin{array}{l}\text { Green } \\
\text { vegetables }\end{array}$ & $<7 ; 7 ;>7$ & $53: 445$ & $39: 480$ & $13: 243$ & 1S & $\begin{array}{c}0.7 \\
(0.3-1.1)\end{array}$ & $\begin{array}{c}0.4 \\
(0.2-0.8)\end{array}$ & $<0.05$ \\
\hline Fresh fruit & $<7 ; 7-13 ;>13$ & $45: 238$ & $48: 466$ & $12: 465$ & 1S & $\begin{array}{c}0.6 \\
(0.4-1.0)\end{array}$ & $\begin{array}{c}0.1 \\
(0.1-0.2)\end{array}$ & $<0.001$ \\
\hline $\begin{array}{l}\text { Wholemeal bread } \\
\text { or pasta }\end{array}$ & $1 ; 2 ; 3$ & $92: 937$ & $13: 230$ & - & $1 S$ & $\begin{array}{c}0.6 \\
(0.4-0.9)\end{array}$ & - & n.s \\
\hline Butter & $1 ; 2 ; 3$ & $41: 647$ & $62: 452$ & $2: 70$ & $1 \$$ & $\begin{array}{c}2.1 \\
(1.4-3.4)\end{array}$ & $\begin{array}{c}0.4 \\
(0.1-1.7)\end{array}$ & n.s \\
\hline Margarine & $1 ; 2 ; 3$ & $89: 982$ & $16: 187$ & - & is & $\begin{array}{c}0.9 \\
(0.5-1.6)\end{array}$ & - & n.s. \\
\hline Oil & $1 ; 2 ; 3$ & $7: 98$ & $98: 971$ & - & 1S & $\begin{array}{c}1.4 \\
(0.6-3.2)\end{array}$ & - & n.s \\
\hline Total fat score & $<5 ; 5 ;>5$ & $41: 480$ & $49: 475$ & $15: 214$ & $1 S$ & $\begin{array}{c}1.1 \\
(0.7-1.8)\end{array}$ & $\begin{array}{c}0.8 \\
(0.4-1.4)\end{array}$ & n.s. \\
\hline Alcohol & $<4 ; 4-6 ;>6$ & $33: 730$ & $18: 237$ & $54: 202$ & is & $\begin{array}{c}1.7 \\
(0.9-3.0)\end{array}$ & $\begin{array}{c}5.8 \\
(3.6-9.3)\end{array}$ & $<0.001$ \\
\hline Coffee & $<2 ; 2 ;>2$ & $41: 438$ & $31: 308$ & $33: 423$ & is & $\begin{array}{c}1.0 \\
(0.6-1.7)\end{array}$ & $\begin{array}{c}0.7 \\
(0.4-1.1)\end{array}$ & n.s. \\
\hline
\end{tabular}

"Number of portions per weeks except for wholemeal bread and fats (subjective scores) and beverages (No. of drinks per day).

†For some variables, the sum of strata does not add up to the total because of missing values.

$\ddagger$ Relative risk estimates adjusted for age and sex.

S Reference category.

$95 \% \mathrm{CI}=0.2-0.4)$. It is likely, therefore, that the association with carotenoids was not specific, but simply reflected a gerierally poorer nutritional status in the cases. Along the same line, an explanation could be offered for the appreciable protection in univariate analyses by milk or meat, which was not observed in studies from the US, ${ }^{12}$ and may simply represent nonspecific indicators of a more favourable diet typical of and restricted to this population, or specific markers of affluence and health awareness.

Besides the limited food list, there are several other limitations in the present study, such as the fact that it was not population-based, or the choice of hospital controls ${ }^{17}$ which has often been criticised particularly in relation to the analysis of lifestyle habits or diet. Although the diagnosis and the case or control status was known to the interviewers, information bias was probably not important, since the role of diet in oral and pharyngeal cancer risk had not gained widespread attention in Italy, and was only one of the issues of the study, thus reducing the scope for differential attention or recall. Further, participation was practically complete, cases and controls came from comparable catchment areas, and the results were consistent across major diagnostic categories of the controls (surgical; orthopaedics; others). In relation to confounding, allowance for major potential distorting factors, including smoking, alcohol and social class indicators 
TАВLE 3 Multivariate relarive risks of oral and pharyingeal cancer in relation to selected indicator foods. Milan, Italy, 1987-89

\begin{tabular}{|c|c|c|c|c|c|}
\hline \multirow[b]{2}{*}{ Food item } & \multirow[b]{2}{*}{ Model } & \multicolumn{3}{|c|}{$\begin{array}{l}\text { Relative risk estimates (and } 95 \% \text { confidence intervals) for frequency of } \\
\text { consumption }\end{array}$} & \multirow[b]{2}{*}{$\begin{array}{l}\text { p value } \\
\text { (Trend) }\end{array}$} \\
\hline & & $\begin{array}{c}\text { (Low) } \\
1\end{array}$ & $\begin{array}{l}\text { (Intermediate) } \\
\quad 2\end{array}$ & $\begin{array}{l}\text { (High) } \\
3\end{array}$ & \\
\hline \multirow[t]{2}{*}{ Milk } & $A^{*}$ & $1+$ & $\begin{array}{c}1.0 \\
(0.6-1.6)\end{array}$ & $\begin{array}{c}0.4 \\
(0.2-0.9)\end{array}$ & n.s. \\
\hline & $\mathrm{B}^{* *}$ & $1 \dagger$ & $\begin{array}{c}1.3 \\
(0.8-2.2)\end{array}$ & $\begin{array}{c}0.5 \\
(0.2-1.1)\end{array}$ & n.s. \\
\hline \multirow[t]{2}{*}{ Meat } & $A^{*}$ & $1 \dagger$ & $\begin{array}{c}1.1 \\
(0.7-1.8)\end{array}$ & $\begin{array}{c}0.5 \\
(0.3-0.9)\end{array}$ & $<0.05$ \\
\hline & $\mathrm{B}^{* *}$ & $1 \dagger$ & $\begin{array}{c}1.4 \\
(0.8-2.4)\end{array}$ & $\begin{array}{c}0.6 \\
(0.3-1.1)\end{array}$ & n.s. \\
\hline \multirow[t]{2}{*}{ Cheese } & $A^{*}$ & $1 \dagger$ & $\begin{array}{c}1.2 \\
(0.7-2.0)\end{array}$ & $\begin{array}{c}0.7 \\
(0.4-1.2)\end{array}$ & n.s. \\
\hline & $\mathrm{B}^{* *}$ & $1 \dagger$ & $\begin{array}{c}1.2 \\
(0.7-2.1)\end{array}$ & $\begin{array}{c}0.8 \\
(0.4-1.4)\end{array}$ & n.s. \\
\hline \multirow[t]{2}{*}{ Carrots } & $A^{*}$ & $1+$ & $\begin{array}{c}0.6 \\
(0.4-1.1)\end{array}$ & $\begin{array}{c}0.4 \\
(0.2-0.8)\end{array}$ & $<0.01$ \\
\hline & $B^{* *}$ & $1 \dagger$ & $\begin{array}{c}0.8 \\
(0.4-1.4)\end{array}$ & $\begin{array}{c}0.6 \\
(0.4-1.1)\end{array}$ & n.s. \\
\hline \multirow[t]{2}{*}{ Green vegetables } & $A^{*}$ & $1 \dagger$ & $\begin{array}{c}0.9 \\
(0.6-1.5)\end{array}$ & $\begin{array}{c}0.6 \\
(0.3-1.2)\end{array}$ & n.s. \\
\hline & $\mathrm{B}^{* *}$ & $1 \dagger$ & $\begin{array}{c}1.1 \\
(0.6-1.8)\end{array}$ & $\begin{array}{c}1.0 \\
(0.5-2.0)\end{array}$ & n.s. \\
\hline \multirow[t]{2}{*}{ Fresh fruit } & $A^{*}$ & $1 \dagger$ & $\begin{array}{c}0.6 \\
(0.4-1.0)\end{array}$ & $\begin{array}{c}0.2 \\
(0.1-0.4)\end{array}$ & $<0.001$ \\
\hline & $\mathrm{B}^{* *}$ & $1 \dagger$ & $\begin{array}{c}0.7 \\
(0.4-1.3)\end{array}$ & $\begin{array}{c}0.3 \\
(0.1-0.5)\end{array}$ & $<0.001$ \\
\hline \multirow[t]{2}{*}{ Alcohol } & $A^{*}$ & $1 \dagger$ & $\begin{array}{c}1.5 \\
(0.8-3.0)\end{array}$ & $\begin{array}{c}3.6 \\
(2.0-6.4)\end{array}$ & $<0.001$ \\
\hline & $\mathrm{B}^{* *}$ & $1 \dagger$ & $\begin{array}{c}1.5 \\
(0.8-3.0)\end{array}$ & $\begin{array}{c}3.8 \\
(2.0-7.0)\end{array}$ & $<0.001$ \\
\hline
\end{tabular}

*Derived from multiple logistic regression models including terms for sex, age, area of residence, education, social class, and smoking.

* Derived from models including simultaneously the above non-dietary covariates and all food items listed in this table.

†Reference category.

explained only part of the dietary associations observed.

These and other limitations, therefore, do not totally eclipse the major finding of the study, i.e. the presence of strong associations between several indicators of a less affluent diet and the risk of cancer of the oral cavity and pharynx. Further, the observation that fruit appears to be a particularly important protective factor against these forms of cancer is of potential interest, in terms of aetiological clues and preventive implications.

\section{ACKNOWLEDGEMENTS}

This work was conducted within the framework of the National Research Council (CNR), Applied Projects 'Oncology' (Contract no. 87.01544.44) and 'Risk Factors for Disease' and with the contributions of the Italian Association for Cancer Research and of the

TABLE 4 Relative risks* of oral and pharyngeal cancer in relation to frequency of consumption of fresh fruit in separate strata of tobracco and alcohol consumption. Milan, ILaly, 1987-89

\begin{tabular}{|c|c|c|c|c|}
\hline \multirow[b]{2}{*}{ Fresh fruit } & \multicolumn{2}{|c|}{ Tobacco } & \multicolumn{2}{|c|}{ Atcohol (drinks/day) } \\
\hline & $\begin{array}{l}\text { Never/ex smokers } \\
(\text { No. }=19)\end{array}$ & $\begin{array}{l}\text { Current smokers } \\
(\text { No. }=86)\end{array}$ & $\begin{array}{c}\leq 6 \\
(\text { No. }=51)\end{array}$ & $\begin{array}{c}>6 \\
(\text { No. }=54)\end{array}$ \\
\hline Low & it & $1+$ & $1+$ & $1 \dagger$ \\
\hline Intermediate & 0.3 & 0.7 & 0.8 & 0.7 \\
\hline High & 0.1 & 0.1 & 0.1 & 0.2 \\
\hline
\end{tabular}

"Mantel-Haenszel estimates adjusted for age, sex and, respectively, alcohol and tobacco.

tReference category. 
Italian League against Tumour, Milan. The Authors wish to thank Mrs J. Baggott, Mrs M P Bonifacino, and the G A Pfeiffer Memorial Library for editorial assistance.

\section{REFERENCES}

'Paterson D R. A clinical type of dysphagia. J Laryng 1919; 34: $289-91$.

${ }^{2}$ Wynder E L, Fryer $J H$. Etiologic considerations of PlummerVinson (Paterson-Kelly) syndrome. Ann Intern Med 1958; 49: $1106-28$.

${ }^{3}$ Larsson L G, Sandstrom A, Westling P. Relationship of PlummerVinson disease to cancer of the upper alimentary tract in Sweden. Cancer Res 1975; 35: 3308-16.

+ Wynder E L, Bross J J, Feldman R M. A study of the etiologic fac. tors in cancer of the mouth. Cancer 1957; 10: 1300-23.

s Wynder E L, Hultberg S, Jacobsen F, Bross I J. Environmental factors in cancers of the upper alimentary tract. A Swedish study with special reference to Plummer-Vinson's (Paterson-Kelly) syndrome. Cancer 1957; 10: 470-87.

'Jacobs A, Cavill 1 A. Pyridoxine and riboflavin status in the Paterson-Kelly syndrome. Br J Haemalol 1968; 14: 153-60.

'Darby W J, McNutt K W, Todhunter E N. Niacin. Nutr Rev 1975; 33: 289-97.

${ }^{B}$ Graham S, Dayal H, Rohrer T, et al. Dentition, diet, tobacco and alcohol in the epidemiology of oral cancer. I Natl Cancer Inst 1977; 59: 1611-8.

'Marshall J, Graham S, Mettlin C, Shedd D, Swanson M. Diet in the epidemiology of oral cancer. Nutr Cancer 1982; 3: 145-9.

${ }^{10}$ Winn D M, Zeigler R G, Pickle L W, Gridley G, Blot W J, Hoover R $N$. Diet in the etiology of oral and pharyngeal cancer among women from the Southern United States. Cancer Res 1984; 44: 1216-22.

" Franco E L, Kowalski L P, Oliveira B V, et al. Risk factors for oral cancer in Brazil: a case-control study. Int J Cancer 1989; 43: 992-1000.

${ }^{12}$ McLaughlin J K, Gridley G, Block G, et al. Dictary factors in oral and pharyngeal cancer. J Nall Cancer Inst 1988; 80: 1237-43.

${ }^{13}$ Cislaghi C, Decarli A, La Vecchia C. Laverda N, Mezzanotte G, Smans N. Dati, indicatori emappe di monalità tumorale. Data, statistics and maps on cancer monality. Italia 1975/1977. Bologna, Pitagora Editrice, 1986.
${ }^{14}$ Levi F, Maisonneuve P, Filiberti R, La Vecchia C, Boyle P. Cancer incidence and mortality in Europe. Soz Praventivmed 1989; 34 Suppl 2: S1-S84.

${ }^{15}$ La Vecchia C, Ferraroni M, Negri E, el al. Coffee consumption and digestive tract cancers. Cancer Res 1989; 49: 1049-51.

16 Breslow N E, Day N E. Statistical methods in cancer research, vol. 1: The analysis of case-control studies. IARC Sci Publ 1980; 32: $5-338$.

${ }^{17}$ Mantel N, Haenszel W. Statistical aspects of the analysis of data from retrospective studies of disease. I Nall Cancer Inst 1959; 22: $719-48$.

12 Mantel N. Chi-square tests with one degree of freedom; extensions of the Mantel-Haenszel procedure. J Am Stat Assoc 1963; 58 : 690-700.

${ }^{19}$ Baker $\mathrm{R}$ J, Nelder J A. The GLIM system release 3. Oxford: Numerical Algorithms Group, 1978.

Wynder E L, Stellman S D. Comparative epidemiology of tobaccorelated cancers. Cancer Res 1977; 37: 4608-22.

"I Btot W J, McLaughlin J K, Winn D M, er al. Smoking and drinking in relation to oral and pharyngeal cancer. Cancer Res 1988; 48: 3282-7.

${ }^{n}$ Merletti F, Boffetta P, Ciccone G, Mashberg A, Terracini B. Role of tobaceo and alcoholic beverages in the etiology of cancer of the oral cavity/oropharynx in Torino, Italy. Cancer Res 1989; 49: 4919-24.

${ }^{2}$ Decarli A, Liati P, Negri E. Franceschi S, La Vecchia C. Vitamin A and other dietary factors in the etiology of esophageal cancer. Nutr Cancer 1987; 10: 29-37.

"2 Tuyns A J, Riboli E, Doornbos G, Péquignot G. Diet and esophageal cancer in Calvados (France). Nurr Cancer 1987; 9: 81-92.

${ }^{y}$ De Stefani E, Correa A, Oreggia F, et al. Risk factors for laryngeal cancer. Cancer 1987; 60: 3087-91.

${ }^{20}$ La Vecchia C, Negri E, D'Avanzo B, Franceschi S, Decarli A, Boyle P. Dietary indicators of laryngeal cancer risk. Cancer Res 1990; S0: $4497-5000$.

${ }^{n}$ C.O.N.A.I. $A B C$ per l'educazione alimentare: Manuale. Milano, CLESAV, 1983.

Rossing M A, Vaughan T L, McKnight B. Diet and pharyngeal cancer. Int J Cancer 1989; 44: 593-7.

(Revised version received July 1990) 